\title{
Capacity to make health care decisions: its importance in clinical practice
}

\author{
J. G. WONG, ${ }^{1}$ I. C. H. CLARE, M. J. GUNN AND A. J. HOLLAND
}

From the Department of Psychiatry (Section of Developmental Psychiatry), University of Cambridge; and Department of Academic Legal Studies, Nottingham Law School, Nottingham Trent University, Nottingham

\begin{abstract}
Background. Assessment of capacity plays a pivotal role in determining when decisions need to be made on behalf of an individual. It therefore has major clinical management implications for health care professionals and civil liberties implications for the person concerned. In many countries, there is a presumption that adults have the capacity to make health care decisions. However, in persons with a mental disability, capacity may be temporarily or permanently impaired.
\end{abstract}

Methods. A selective review is presented which considers: ( $i$ ) the broad approaches taken to determining capacity; (ii) the abilities commonly assessed in determining capacity; and (iii) the principles underlying health care decision-making for adults who are without capacity.

Results. Capacity is a functional concept, determined by the person's ability to understand, retain, and weigh up information relevant to the decision in order to arrive at a choice, and then to communicate that choice. We have reviewed the studies that examined decision-making abilities in people with dementia, chronic mental illness or intellectual disabilities. Approaches to decisionmaking in adults who lack capacity include: anticipatory decisions made through advance health care statements or decisions by proxy based on 'best interests' or 'substituted judgement'.

Conclusions. The understanding of clinical and legal aspects of capacity is still developing. This paper examines current concepts of capacity and decision-making on behalf of those without capacity. We propose a framework, in line with current ethical and legal guidelines, as an aid to clinicians when they are seeking consent for a health care intervention.

\section{INTRODUCTION}

A basic legal and ethical principle in democratic countries is that adults have the right to make decisions affecting their own lives. However, this right to self-determination is only meaningful if the person is appropriately informed, is free to make decisions without coercion and has the ability or 'capacity' to make the decision. Where an individual may not have capacity, there may exist both a difficult ethical dilemma between respect for autonomy and the individual's need for care and protection from harm, and uncertainty as to an appropriate and legal course of action.

1 Address for correspondence: Dr J. G. Wong, Department of Psychiatry, University of Hong Kong, Queen Mary Hospital, Pokfulam, Hong Kong.
In mental health services and in services for people with intellectual disabilities or with traumatic or progressive disorders of the brain, the issue of capacity is particularly salient. $A$ priori, the difficulties involving thought, affect and cognition, which characterize and are associated with such serious mental disabilities, seem likely to impair some of the abilities required for autonomous decision-making (Freedman et al. 1991; Marson et al. 1994; Appelbaum \& Grisso, 1995; Jones, 1995; Murphy \& Clare, 1995; Brabbins et al. 1996). It is, therefore, important that psychiatrists and other mental health professionals are familiar with concepts of capacity and its evaluation, not only for their own clinical practice, but also when providing advice to medical or surgical colleagues, and as expert witnesses in court.

Different legal jurisdictions may approach 
issues surrounding capacity in different ways. However, ethical difficulties in relation to decision-making among people whose abilities are impaired are universally relevant. Although the capacity to make decisions is central to most aspects of life, in this paper we focus on one particular area: capacity to give or withhold consent to health care interventions. The following issues are considered: $(i)$ the broad approaches taken to determining capacity in adults; (ii) the abilities commonly assessed in determining capacity; and (iii) the principles underlying health care decision-making for adults who are without capacity. While reference is made to a number of jurisdictions, there is a particular focus on England and Wales where reform of the current law has been advocated and is being considered (Law Commission, 1995; Lord Chancellor's Department, 1997). We conclude by presenting a framework that will aid clinicians in assessing capacity and seeking consent in an ethically and legally defensible manner.

\section{THE RELEVANCE OF CAPACITY}

Issues relating to decision-making capacity are becoming increasingly important in mental health practice, not just for ethical and legal reasons, but also because of demographic and social changes. In most developed countries, including the United Kingdom, the population of older people is expanding (United Nations, 1979; Harris, 1997). Since the risk of dementia increases exponentially with age (Kay, 1991), it is expected that there will be an increase in the prevalence of dementia. At the same time, accompanying social policies of de-institutionalization and care in the community (for example, in England and Wales, the National Health Service and Community Care Act 1990) have enabled a large number of people with mental disabilities to be resettled from hospital (Audit Commission, 1994; Mansell, 1997), thus potentially increasing the opportunities and scope for decision-making. Moreover, policies that foster the empowerment of disadvantaged persons (for example, United Nations, 1994) are increasingly being adopted. An important policy objective is to enable or encourage such persons to exercise their capacity to the greatest extent possible. Where decisions need to be made for an individual, the emphasis is on adopting the least restrictive alternative taking into account, where possible, the person's previously expressed preferences. These principles are expressed in mental health and disability law in most developed countries (a full list of statutes embodying these principles is given in Creyke, 1995; Law Commission (England and Wales), 1995, para. 2.46; Scottish Law Commission, 1995, paras. 1.5 and 1.27).

In England and Wales, and in most other common law jurisdictions, an adult is presumed to have capacity to give or withhold consent until proved otherwise. This right to autonomy exists whether the reasons for making the choice are rational, irrational, unknown, or even nonexistent, and regardless of whether the outcome might be detrimental to the person (Re T (adult: refusal of treatment) [1992] 4 All England Law Reports, 649) or to a viable foetus (St George's Healthcare National Health Service Trust v S, The Times Law Report, May 8, 1998). Based on the principle that every person's body is inviolate, health care interventions, even if intended for the individual's benefit, which are carried out without his or her consent may constitute a civil or criminal offence of assault or battery.

Nevertheless, the general presumption of capacity is refutable. An adult may be without capacity through a life-long mental disability, such as an intellectual disability. Capacity may have been attained but lost through trauma or the onset of dementia, or may fluctuate as the result of temporary factors, such as acute mental illness, unconsciousness, confusion, or the effects of fatigue, pain or drugs.

\section{WHAT IS CAPACITY?}

\section{Approaches to determining capacity}

Capacity is the pivotal issue in balancing the right to freedom of decision-making and the right to protection from harm. It distinguishes the person who is capable of making a decision and whose choice must, therefore, be respected, from one who requires others to make decisions for him or her. It is a major challenge to set a threshold for capacity that is neither so low as to fail to offer adequate protection to those who are vulnerable nor so high that it restricts the right to self-determination of a person with capacity. Much consideration has been given 
internationally to the approaches that might be used to determine capacity (Roth et al. 1977; President's Commission, 1983; Weisstub, 1990; Appelbaum \& Grisso, 1995; Law Commission 1995; Scottish Law Commission, 1995; Verma \& Silberfeld, 1997). Three broad approaches have been distinguished (President's Commission, 1983; Weisstub, 1990; Hoggett, 1994). These are:

\section{Outcome}

This approach uses the consequence of the decision-making process as the criterion for determining capacity. The implication is that an individual who makes a decision that is contrary to conventional wisdom or the opinion of the treatment-provider is likely to be viewed as being without capacity. Despite arguments that it protects people from the consequences of unsound decisions (Hoggett, 1994), this approach has been firmly rejected by case law in a number of jurisdictions (see cases quoted in Kennedy \& Grubb, 1994, pp. 135-140) as it gives little meaning to self-determination.

\section{Status}

In this approach, a person's capacity is determined by his or her membership of a specific population. Assumptions are made about an individual's decision-making on the basis of some characteristic, for example, chronological age, estimated 'mental age' or psychiatric diagnosis. This approach assumes, first, that a group sharing a particular characteristic is homogeneous and, secondly, that all decisionmaking involves a similar level of demand upon the decision-maker. Neither of these assumptions is supported empirically (Morris et al. 1993; Grisso \& Appelbaum, 1995 a : Marson et al. 1995a, b). In England and Wales, the status approach has been rejected both in case law (Re C (Refusal of Treatment) [1994] 1 All E.R. 819) and by the Mental Health Act 1983 Code of Practice (Department of Health and Welsh Office, 1993).

\section{Functional}

In many jurisdictions, this approach has attracted the most informed support (President's Commission, 1983; Weisstub, 1990; Law Commission, 1995; Scottish Law Commission, 1995).
It is based on establishing the extent to which the person's understanding, knowledge, skills and abilities meet the demands of the task involved in making a particular decision within a given legal context (Grisso, 1986). Capacity is, therefore, decision-specific and time-specific, rather than global or permanent. There are two important implications. First, although evidence, from standardized assessments, of abnormal mental states or cognitive impairments is informative, it cannot, and should not, replace a specific assessment of the person's decisionmaking abilities in relation to the particular decision at issue (Marson et al. 1994; Grisso \& Appelbaum, 1998). Secondly, where it appears that a person is without capacity, consideration needs to be given to the possibility of improving the relevant functional abilities. This may be achieved by education (Chaplin \& Kent, 1998), treatment of the underlying disorder (Grisso \& Appelbaum, 1995a) and/or by simplifying the task through presenting treatment information using: (a) simpler language (Tymchuk et al. 1986); (b) illustrations (Hollins et al. 1996); or (c) in small 'chunks', which are more easily processed (Grisso \& Appelbaum, $1995 a)$.

A functional approach is, however, not without problems. First, it is time-consuming since, in theory, everyone should have a capacity assessment each time they make a decision (Hoggett, 1994). Secondly, legal standards for capacity vary between jurisdictions and there is so far no unanimous agreement on the abilities that comprise capacity, let alone how these might be assessed in practice (Grisso, 1986; Gunn, 1994; Appelbaum \& Grisso, 1995; Wong, 1997). Thirdly, there is uncertainty about the threshold at which the discrepancy between the decision-maker's functional abilities and the demands of the particular decision is deemed to constitute incapacity. This ambiguity is perhaps inevitable as individuals and societies hold different views about the balance between the conflicting interests of respect for autonomy and protection of vulnerable people from harm.

It has been proposed that the three approaches might be integrated. For example, an outcome and functional approach may be combined in 'sliding scale' models (Roth et al. 1977; Drane, 1984; Schwartz \& Blank, 1986; Weisstub, 1990) where the threshold for capacity depends on the 
complexity of the decision, the significance of its outcome, or a combination of the two. Despite its superficial attractiveness, it has been argued that a sliding scale may simply miss the point (Gunn, 1994). As the 'desirability' of the outcome of the decision and its 'dangerousness' are often determined by the clinician, the focus of capacity shifts away from the patient's abilities and values; the approach may be too paternalistic (Glass, 1997). Moreover, determination of the way in which, and by whom, the threshold for capacity should be decided and the validity of such multiple thresholds remain practical hurdles.

An alternative proposal is that the status and functional approaches are combined so that a functional assessment is only carried out when a person's status places the presumption of capacity in doubt (Hoggett, 1994). Though controversial (Carson, 1993), on the grounds that it may be prejudicial to people with disabilities, this combination of approaches has been proposed, following extensive consultation, in both England and Wales (Law Commission, 1995) and Scotland (Scottish Law Commission, 1995).

\section{Abilities relevant to capacity}

The abilities that are relevant to decision-making have been widely considered in both the clinical (Roth et al. 1977; Grisso, 1986; Appelbaum \& Grisso, 1995; Grisso \& Appelbaum, 1998) and legal literature (Gunn, 1994; President's Commission; Law Commission, 1995; Scottish Law Commission, 1995; Weisstub, 1990). Although a universally accepted set of standards for capacity remains elusive, there is now an emerging consensus. The following abilities are most commonly cited as relevant: (i) communicating a choice; (ii) understanding relevant information; (iii) retaining the information; (iv) appreciating the personal significance of treatment information; $(v)$ reasoning and rational manipulation of information to arrive at a decision (Appelbaum \& Grisso, 1988; Weisstub, 1990; Law Commission, 1995; Berg et al. 1996). Each of these abilities, and its relevance to mental health practice, will be examined in turn.

\section{(i) Communicating a choice}

This is the least stringent standard as it requires only the ability to make a response about a particular decision (Roth et al. 1977; Appelbaum
\& Grisso, 1995; Law Commission, 1995). Difficulties in communicating a choice may arise from a wide variety of sources, for example, extreme ambivalence, thought disorder, or memory problems (Appelbaum \& Grisso, 1988; Grisso \& Appelbaum, 1995a; Marson et al. 1995b), impairments in verbal expression (Benson \& Ardila, 1996; Rapin, 1996), or in mute or stuporose states.

The ability to communicate a choice is a necessary, but not sufficient, standard of capacity. The mere expression of a choice does not indicate whether consideration has been given to issues such as the achievement of personal goals and, by itself, may fail to provide adequate protection for the well-being of vulnerable persons. The Law Commission (1995), in its proposed legislation, suggests an obligation on treatment providers to take all practicable steps to enable the person to communicate. Where appropriate, these should include the use of augmentative or alternative forms of communication (Kiernan, 1985; Beukelman \& Mirenda, 1992; Ambalu, 1997).

\section{(ii) Understanding information relevant to the treatment}

This standard is included in almost all concepts of capacity across jurisdictions and is the least controversial. Generally, the threshold for achieving the standard is low. For health care decisions, only an understanding, in 'broad terms' and 'simple language', of the nature and purpose of the treatment is required (Chatterton $v$ Gerson [1081] Queen's Bench 432; Law Commission, 1995, para 3.18), rather than any detailed knowledge.

Studies using standardized disclosures have demonstrated difficulties in understanding information about treatment among people with mental disorders, primarily schizophrenia or depression (Grossman \& Summers, 1980; Irwin et al. 1985; Schachter et al. 1994; Grisso \& Appelbaum, 1995a), dementia (Marson et al. 1995b) and intellectual disabilities (Morris et al. 1993), with an association between the severity of the mental disability and the impairment of understanding. However, the relevance or familiarity of the material may be important. People with schizophrenia or depression tend to demonstrate better understanding of material relating to their own diagnosis than to medical 
conditions which they have not experienced (Grisso \& Appelbaum, 1991).

\section{(iii) Retaining relevant information}

The Law Commission included an inability to retain relevant information in their proposed definition of incapacity. This standard is controversial since neither the period during which information should be retained nor the form in which it should be retained has been specified. In any case, the criterion may be redundant (Jones \& Keywood, 1996) on the grounds that, if information is not retained, the person is unlikely to be able to demonstrate understanding of the relevant information; consequently, he or she would then be deemed to lack capacity.

\section{(iv) Manipulating information rationally}

This refers to the ability to weigh the risks and benefits of different options. It may be impaired by various symptoms associated with mental disorders, for example, delusions of persecution or grandeur, as well as the concrete thinking and problem-solving difficulties associated with intellectual disabilities or dementia (Murphy \& Clare, 1995). In common law, a seemingly irrational choice is not, in itself, indicative of incapacity. The introduction of a 'rationality' standard has been viewed with caution as standards of rationality are often based on the subjective judgement of assessors (Tancredi, 1982), and hence may allow a covert adoption of the outcome approach. Consequently, commentators emphasize that the standard should focus on the process by which the individual reaches a decision (Appelbaum \& Grisso, 1988, 1995; Gunn, 1994), not its outcome. Jones \& Keywood (1996) argue that the interpretation of this standard should be based on whether the person's decision was a 'rational product' of his or her underlying beliefs, regardless of the unusualness or irrationality of those beliefs. An alternative, more stringent, standard is the possession of long-held beliefs that are not the result of a temporary delusion reflecting some current illness (The President's Commission, 1983; Kennedy, 1992).

Nevertheless, some practical and conceptual problems remain. It is, for example, doubtful whether the rationality of a decision-making process can ever be assessed without consideration of its outcome. Similarly, the period required for beliefs to be considered longstanding or stable has never been operationalized. Moreover, a focus on whether the individual's decision is congruent with his or her underlying belief system ignores issues surrounding the social acceptability of the belief system or whether such a system would be regarded as pathological. As has been pointed out (Kopelman, 1990), judgements about belief systems are not value-free. In making assessments, clinicians should be aware of their own beliefs, and adopt a structured approach to minimize the impact of their own value systems (Law Commission, 1991, para. 2.44).

(v) Appreciating the situation and its likely consequences

In making a health care decision, 'appreciation' differs from factual understanding. It requires that the person recognizes that he or she has a disorder to which the particular treatment may apply. Difficulties in appreciation or lack of insight are often considered to be core components of the major psychiatric disorders (Carpenter et al. 1976; Bursztajn et al. 1991; Grisso \& Appelbaum, 1995a). While such problems may also affect people with dementia and intellectual disabilities, they must be viewed in the context of carers' apparent reluctance to provide information to people with these diagnoses about their disorders (Goldsmith, 1996; Maguire et al. 1996; Todd \& Shearn, 1997).

Though there is some consensus that the above abilities are relevant to health care decision-making, the 'weighting' to be given to each standard remains uncertain. This is important as the use of different standards, or combinations of standards, affects the identity and proportion of persons who are without capacity (Grisso \& Appelbaum, 1995b).

\section{DECISION-MAKING FOR ADULTS WHO DO NOT HAVE CAPACITY}

Where an individual is without capacity, mechanisms need to be in place to ensure that he or she is not deprived of necessary treatment. There are three broad approaches to decisionmaking for an adult who is unable to make a particular health care decision: anticipatory decision-making by the person him or herself in 
the form of advance health care statements, and proxy decision-making by others, based on either 'substituted judgement' or 'best interests'.

\section{Advance health care statements}

Advance statements of health care are most respectful of an individual's right to selfdetermination because they are direct expressions of personal wishes. Provision for the legal acceptance of both advance decisions about health care and appointment of proxies is already in place in many common law jurisdictions (for example: Florida in the USA, Ontario and Manitoba in Canada, Victoria in Australia; for details, see Kennedy \& Grubb, 1994).

In England and Wales, informed advance refusals of treatment are legally binding in common law provided that they are made by a person who has capacity to make that decision, and are used in the circumstances that are clearly specified in the advance refusal $(\operatorname{Re} C$ [1994] see above; British Medical Association, 1995; Dormer, 1997). Recently, in both England and Wales (Law Commission, 1995, Part V; Lord Chancellor's Department, 1997) and Scotland (Scottish Law Commission, 1995, para. 5.50), it has been proposed that the law governing this area should be placed on a clear statutory basis. Proposals to put advance refusals on a statutory basis have aroused controversy because of concerns about possible links with the legalization of euthanasia. However, it is clear that at present only advance refusals of treatment are legally binding. Euthanasia, which involves an intentional act to end a patient's life, remains unlawful (Lord Chancellor's Department, 1997).

The legality, in England and Wales, of other forms of advance health care statements is less clear. Anticipatory appointment of health care proxies through a 'continuing' or 'enduring' power of attorney has no legal force in England and Wales at present, but is being considered for legislation (Law Commission, 1995, Part VII). Meanwhile, there has been increasing interest in the development of psychiatric advance directives or 'crisis cards' (Halpern \& Szmukler, 1997; Sutherby \& Szmukler, 1998). These are drafted while the individual is clinically well and provide instructions relating to the person's care in case of a relapse or crisis. While their use is still restricted, and as yet they have no legal force, their informal use, as an aid to selfadvocacy, is likely to become more common (Department of Health, 1993).

Despite the advantages of advance health care decisions, there are practical limitations. First, anticipating the circumstances in which the statement will be applied may be a demanding task. Secondly, they cannot be used for adults who may never develop the capacity to make relevant decisions. Thirdly, public knowledge about the possibility of making advance health care decisions is at present limited, although this can be changed relatively easily through education.

\section{Decision-making by proxy}

Two general approaches have been adopted for proxy decision-making: 'best interests' and 'substituted judgement'. The 'best interests' approach is based on the ethical principle of beneficence. The 'substituted judgement' approach requires the proxy to make a decision which best reflects the person's choice if he or she had capacity.

In England and Wales, the 'best interests' test is favoured. At present, no person or court can give consent to treatment of an adult who is without capacity (for an analysis of the legal background, see Law Commission, 1991, pp. 55-90). The only legal framework is that provided by the common law doctrine of necessity. The leading case is that of $R e F$ (Mental Patient: Sterilization) ([1990] 2 AC 1) in which the House of Lords ruled that treatment of an adult who is unable to make a health care decision may be carried out if, in accordance with a practice accepted at the time by a responsible body of appropriately skilled medical opinion, it is necessary in the 'best interests' of the person. This approach also permits other action, such as the admission to hospital of a person who lacks capacity to make this decision, but is not objecting, without use of the Mental Health Act 1983 ( $R$ v Bournewood Community and Mental Health NHS Trust, ex parte L [1998] 3 All E.R. 289).

More formal assessments of what constitutes 'best interests' may be required when the proposed intervention is neither a necessity nor an emergency, and is particularly controversial. Examples include the sterilization of women for contraceptive reasons, organ donation, or any 
other non-therapeutic procedure. In such situations, the House of Lords has advised that it would be good practice to seek a declaratory judgement from the court on the legality of the intervention.

The definition of 'best interests' in $R e F$ is narrowly confined to the medical interests of patients and is intended 'to save their lives or to ensure improvement or prevent deterioration in their physical and mental health' (Re $F$, per Lord Brandon). There is now increasing support for the view that 'best interests' should encompass broader considerations such as the previously expressed wishes of the individual, the views of significant others, and the 'least restrictive' action (Law Commission, 1995, paras. $3.25,3.28$ ), extending the approach to include elements of 'substituted judgement'.

There are also inherent difficulties for the 'substituted judgement' approach. It has been suggested (Ouslander et al. 1989) that potential proxies are poor predictors of the health care decisions of people who may become mentally incapacitated. For example, where adult children have claimed to be able to represent a parent's views, their opinions are often based on vague impressions, with a lack of agreement between siblings (Sonnenblick et al. 1993). Moreover, conflicts of interest may lead to some proxies acting to serve their own motives.

Decision-making may be made through informal proxies, such as family members or carers, by proxies appointed by the patient through a legal mechanism, by court-appointed guardians, or by the court itself. It seems appropriate to adopt a hierarchical approach in which the severity of the implications of the particular decision determines the level of formality and regulation of proxy decisionmaking. This is certainly the approach adopted in many other democracies (for example Australia: Creyke, 1995) and is currently under consideration for Scotland (Scottish Law Commission, 1995) and England and Wales (Law Commission, 1995; Lord Chancellor's Department, 1997). While a consideration of the full range of possible legal mechanisms is beyond the scope of this paper, this broad framework illustrates the challenge of achieving a balance between the provision of adequate protection to people without capacity and encumbering their lives with restrictive legal provisions.

\section{Exceptions to a capacity-based approach}

While the autonomy of 'capable' individuals is a general rule in England and Wales, not all health care legislation reflects a capacity-based approach. Probably the most important exception to the general rule is the Mental Health Act 1983, which provides a legal framework to enable individuals to be detained in hospital for the assessment and treatment of mental disorders. With some exceptions, such as psychosurgery (s. 57), or the long-term administration of medicine (s. 58), where the person's consent must be sought, the individual's capacity to give or withhold consent to such treatment is ultimately irrelevant. The grounds for admission to hospital under the Act are the patient's health needs or danger to himself or herself or danger to others (s. 2), as judged by medical practitioners and approved social workers.

Similarly, a utilitarian rationale underlies the public health legislation (e.g. the National Assistance Act 1948; the Public Health (Control of Diseases) Act 1984) authorizing a range of interventions (for example, removal from home, detention, and examination, though not treatment) which do not require the individual's consent.

\section{CONCLUSIONS}

Capacity is of central importance in decisionmaking about health care interventions. As this review illustrates, however, when the presumption of capacity may not, or cannot, be sustained, important philosophical, legal, and practical issues are raised to which there are no straightforward solutions. Each such case presents a challenge because of the need to balance respect for an individual's autonomy and protection of vulnerable members of society from harm.

In most cases, the health care practitioner proposing a particular intervention is responsible for determining whether the person has the capacity to give or withhold consent to that treatment. Given the difficulties outlined in this review, how may this task best be achieved? In Fig. 1, we present a framework to assist in the process of making such assessments.

The framework, which provides general guidance on treatment decisions and some other legally-significant decisions, is intended to apply 


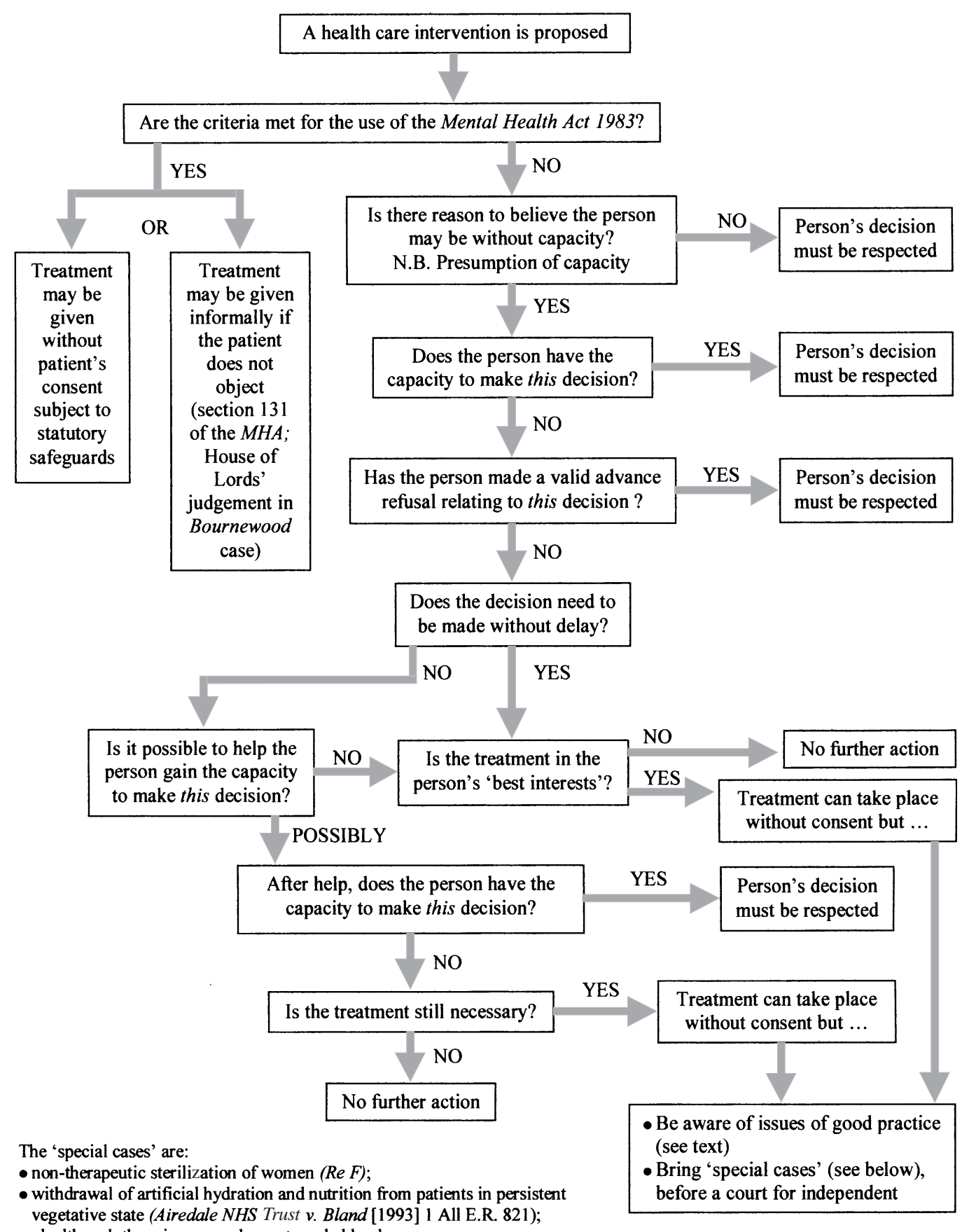

- non-therapeutic sterilization of women $(\operatorname{Re} F)$;

withdrawal of artificial hydration and nutrition from patients and, although there is no case law yet, probably also

- tissue donation.

FIG. 1. An aid to clinicians in seeking consent to health care intervention: what is ethically and legally defensible? 
primarily to clinicians in England and Wales (British Medical Association/The Law Society, 1995), but the general principles may be useful in other jurisdictions if the local legal criteria for capacity are addressed. Attention needs to be paid to issues of good practice when considering treatment of an adult who does not have capacity. Consideration should be given to views of the person concerned even though he or she is considered legally without capacity to determine what happens. The person's liberty, privacy and dignity should be maintained as far as possible. Whenever appropriate, the views of the person's significant others and the opinion of other professionals should be sought. This is particularly important in the process of capacity assessment and in maximizing capacity.

Since capacity is a legal construct, ultimately it is for a court to decide whether or not an individual is 'capable' of making a particular health care decision. However, the framework presented here will, at least, enable clinicians to make assessments which, if fully documented, will be ethically, as well as legally, defensible.

This paper was written as the initial element of a project on capacity to consent to treatment, funded by the Nuffield Foundation; we are grateful for their support. We would also like to thank Dr Tom Dening and Dr Claire Lawton for their advice.

\section{REFERENCES}

Ambalu, S. (1997). Communication. In Adults with Intellectual Disabilities. A Practical Approach for Health Professionals (ed. J. O'Hara and A. Sperlinger), pp. 45-60. John Wiley \& Sons: Chichester.

Appelbaum, P. S. \& Grisso, T. (1988). Assessing patient's capacity to consent to treatment. New England Journal of Medicine 319, 1635-1638.

Appelbaum, P. S. \& Grisso, T. (1995). The MacArthur Treatment Competence Study. I. Mental illness and competence to consent to treatment. Law and Human Behavior 19, 105-126.

Audit Commission (1994). Finding a Place. A Review of Mental Health Services for Adults. HMSO: London.

Benson, D. F. \& Ardila, A. (1996). Aphasia. A Clinical Perspective. Oxford University Press: New York.

Berg, J. W., Appelbaum, P. S. \& Grisso, T. (1996). Constructing competence: formulating standards of legal competence to make medical decisions. Rutgers Law Review 48, 345-396.

Beukelman, D. R. \& Mirenda, P. (1992). Augmentative and Alternative Communication. Management of Severe Communication Disorders in Children and Adults. Paul H. Brookes Publishing Co.: Baltimore.

Brabbins, C., Butler, J. \& Bentall, R. (1996). Consent to neuroleptic medication for schizophrenia: clinical, ethical and legal issues. British Journal of Psychiatry 168, 540-544.
British Medical Association (1995). Code of Practice on Advance Statements about Medical Treatment. British Medical Association: London.

British Medical Association and The Law Society (1995). Assessment of Mental Capacity. Guidance for Doctors and Lawyers. British Medical Association: London.

Bursztajn, H. J., Harding, H. P., Gutheil, T. G. \& Brodsky, A. (1991). Beyond cognition: the role of disordered affective states in impairing competence to consent to treatment. Bulletin of the American Academy of Psychiatry and Law 19, 383-388.

Carpenter, W. T., Bartko, J. J., Carpenter, C. L. \& Strauss, J. S. (1976). Another view of schizophrenia subtypes: a report from the International Pilot Study of Schizophrenia. Archives of General Psychiatry 33, 508-516.

Carson, D. (1993). Disabling Process: The Law Commission's proposals on mentally incapacitated adults' decision-making. Journal of Social Welfare \& Family Law 5, 304-320.

Chaplin, R. \& Kent, A. (1998). Informing patients about tardive dyskinesia. Controlled trial of patient education. British Journal of Psychiatry 172, 78-81.

Creyke, R. (1995). Who Can Decide? Legal Decision-Making for Others. Australian Government Publishing Service: Canberra.

Department of Health (1993). Community Supervision Orders: Government Response to the Fifth Report from the Health Committee (Session 1992-1993). HMSO: London.

Department of Health and Welsh Office (1993). Mental Health Act 1983 Code of Practice. HMSO: London.

Dormer, R. J. (1997). Living wills: the Law. Dispatches 8, 1-3.

Drane, J. F. (1984). Competency to give an informed consent. A model for making clinical assessments. Journal of the American Medical Association 272, 925-927.

Freedman, M., Stuss, D. T. \& Gordon, M. (1991). Assessment of competency: the role of neurobehavioral deficits. Annals of Internal Medicine 115, 203-208.

Glass, K. C. (1997). Redefining definitions and devising instruments: two decades of assessing mental competence. International Journal of Law and Psychiatry 20, 5-33.

Goldsmith, M. (1996). Hearing the Voice of People with Dementia. Jessica Kingsley Publishers: London.

Grisso, T. (1986). Evaluating Competencies: Forensic Assessments and Instruments. Plenum Press: New York.

Grisso, T. \& Appelbaum, P. S. (1991). Mentally ill and non-mentally ill patients' abilities to understand informed consent disclosures for medication. Law and Human Behavior 15, 377-388.

Grisso, T. \& Appelbaum, P. S. (1995a). The MacArthur Treatment Competence Study. III. Abilities of patients to consent to psychiatric and medical treatments. Law and Human Behavior 19, 149-174.

Grisso, T. \& Appelbaum, P. S. (1995b). Comparison of standards for assessing patients' capacities to make treatment decisions. American Journal of Psychiatry 152, 1033-1036.

Grisso, T. \& Appelbaum, P. S. (1998). Assessing Competence to Consent to Treatment: A Guide for Physicians and Other Health Professionals. Oxford University Press: New York.

Grossman, L. \& Summers, F. (1980). A study of the capacity of schizophrenic patients to give informed consent. Hospital and Community Psychiatry 31, 205-206.

Gunn, M. (1994). The meaning of incapacity. Medical Law Review 2 (Spring), 8-29.

Halpern, A. \& Szmukler, G. (1997). Psychiatric advance directives: reconciling autonomy and non-consensual treatment. Psychiatric Bulletin 21, 323-327.

Harris, T. (1997). Projections: a look into the future. Social Trends 27, 15-26.

Hoggett, B. (1994). Mentally incapacitated adults and decisionmaking. The Law Commission's project. In Decision-making and Problems of Incompetence (ed. A. Grubb), pp. 27-40. John Wiley \& Sons: Chichester.

Hollins, S., Bernal, J. \& Gregory, M. Illustrated by Webb, B. (1996). Going to the Doctor. Royal College of Psychiatrists/St George's Hospital Medical School: London. 
Irwin, M., Lovitz, A., Marder, S. R., Mintz, J., Winslade, W. J., Van Putten, T. \& Mills, M. J. (1985). Psychotic patients' understanding of informed consent. American Journal of Psychiatry 142, 1351-1354.

Jones, G. H. (1995). Informed consent in chronic schizophrenia? British Journal of Psychiatry 167, 565-568.

Jones, M. A. \& Keywood, K. (1996). Assessing the patient's competence to consent to medical treatment. Medical Law International 2, 107-147.

Kay, D. W. K. (1991). The epidemiology of dementia: a review of recent work. Review of Clinical Gerontology 1, 55-66.

Kennedy, I. (1992). Consent to treatment: the capable person. In Doctors, Patients and the Law (ed. C. Dyer), pp. 44-71. Blackwell Scientific Publications: Oxford.

Kennedy, I. \& Grubb, A. (1994). Medical Law: Text with Materials, 2nd edn. Butterworths; London.

Kiernan, C. (1985). Communication. In Mental Deficiency: The Changing Outlook 4th edn (ed. A. M. Clarke, A. D. B. Clarke and J. M. Berg), pp. 584-638. Methuen: London.

Kopelman, L. M. (1990). On the evaluative nature of competency and capacity judgements. International Journal of Law and Psychiatry 13, 309-329.

Law Commission (1991). Mentally Incapacitated Adults and DecisionMaking: An Overview (Consultation Paper No. 119). HMSO: London.

Law Commission (1995). Mental Incapacity (Law Commission Report No. 231). HMSO: London,

Lord Chancellor's Department (1997). Who Decides? Making Decisions on Behalf of Mentally Incapacitated Adults (Cm 3803). The Stationery Office: London.

Maguire, C. P., Kirby, M., Coen, R., Coakley, D., Lawlor, B. A. \& O'Neill, D. (1996). Family members' attitudes toward telling the patient with Alzheimer's disease their diagnosis. British Medical Journal; 313, 529-560.

Mansell, J. (1997). 'Better Services' 25 years on. Tizard Learning Disability Review 2 (1), 45-46.

Marson, D. C., Cody, H. A., Ingram, K. K. \& Harrell, L. E. (1995a). Neuropsychologic predictors of competency in Alzheimer's disease using a rational reasons legal standard. Archives of Neurology 52, 955-959.

Marson, D. C., Ingram, K. K., Cody, H. A. \& Harrell, L. E. (1995b). Assessing the competency of patients with Alzheimer's disease under different legal standards. A prototype instrument. Archives of Neurology 52, 949-954.

Marson, D. C., Schmitt, F. A., Ingram, K. K. \& Harrell, L. E. (1994). Determining the competency of Alzheimer patients to consent to treatment and research. Alzheimer Disease and Associated Disorders 8, (suppl. 4), 5-18.

Morris, C. D., Niederbuhl, J. M. \& Mahr, J. M. (1993). Determining the capability of individuals with mental retardation to give informed consent. American Journal of Mental Retardation 98, $263-272$.
Murphy, G. H. \& Clare, I. C. H. (1995). Adults' capacity to make decisions affecting the person: psychologists' contribution. In Handbook of Psychology in Legal Contexts (ed. R. Bull and D. Carson), pp. 97-128. John Wiley \& Sons: Chichester.

Ouslander, J., Tymchuk, A. \& Rahbar, B. (1989). Health care decisions among elderly long-term care residents and their potential proxies. Archives of Internal Medicine 149, 1367-1372.

President's Commission for the Study of Ethical Problems in Medicine and Biomedical and Behavioural Research (1983). Making Health Care Decisions. US Government Printing Office: Washington, DC.

Rapin, I. (1996). Practitioner review: Developmental language disorders: a clinical update. Journal of Child Psychology and Psychiatry 37, 643-655.

Roth, L. H., Miesel, A. \& Lidz, C. W. (1977). Tests of competency to consent to treatment. American Journal of Psychiatry 134, 279-284.

Schachter, D., Kleinman, I., Pendergast, P., Remington, G. \& Schertzer, S. (1994) The effect of psychopathology on the ability of schizophrenic patients to give informed consent. Journal of Nervous and Mental Disease 182, 360-362.

Schwartz, H. I. \& Blank, K. (1986). Shifting competency during hospitalisation: a model for informed consent decisions. Hospital and Community Psychiatry 37, 1256-1260.

Scottish Law Commission (1995). Report on Incapable Adults (Scottish Law Commission Report No. 151). HMSO: Edinburgh. Sonnenblick, M., Friedlander, Y.\& Steinberg, A. (1993). Dissociation between the wishes of terminally ill parents and decisions by their offspring. Journal of American Geriatric Society 41, 599-604.

Sutherby, K. \& Szmukler, G. (1998). Crisis cards and self-help crisis initiatives. Psychiatric Bulletin 22, 4-7.

Tancredi, L. (1982). Competency for informed consent. Conceptual limits of empirical data. International Journal of Law and Psychiatry 5, 51-63.

Todd, S. \& Shearn, J. (1997). Family dilemmas and secrets: parents' disclosure of information to their adult offspring with learning disabilities. Disability and Society 12, 341-366.

Tymchuk, A. J., Ouslander, J. G. \& Rader, N. (1986). Informing the elderly. A comparison of four methods. Journal of the American Geriatrics Society 34, 818-822.

United Nations (1979). Age and Sex Composition by Country 1960-2000. United Nations: New York.

United Nations (1994). The Standard Rules on the Equalization of Opportunities for Persons with Disabilities. United Nations: New York.

Verma, S. \& Silberfeld, M. (1997). Approaches to capacity and competency: the Canadian view. International Journal of Law and Psychiatry 20, 35-34.

Weisstub, D. (1990). Enquiry on Mental Competency: Final Report. Queen's Printer: Toronto.

Wong, J. (1997). Assessment of capacity to make treatment decision in adults with learning disabilities. Tizard Learning Disability Review, 2 (3), 35-39. 